\title{
Analysis of Vibration During Turning Process of Different Materials
}

\author{
Á. SARANKÓ1 ${ }^{1}$ G. KALÁCSKA² ${ }^{2}$ R. KERESZTES ${ }^{3}$ \\ 1Szent István University, Faculty of Mechanical Engineering Technology, saranko.adam@gmail.com \\ ${ }^{2}$ Szent István University, Faculty of Mechanical Engineering Technology, kalacska.gabor@gek.szie.hu \\ ${ }^{3}$ Szent István University, Faculty of Mechanical Engineering Technology, keresztes.robert@gek.szie.hu
}

Abstract. In this article, we would like to introduce the problems caused by vibrations in case of polymer turning processes. Nowadays there is a lot of research in this topic, to avoid the unnecessary phenomena of vibrations. The two most common methods are the Spindle Speed Variation (SSV), and the Vibration Assisted Machining (VAM). In case of SSV, the CNC machine can increase and decrease the speed of spindle continuously during turning which can significantly reduce the effects of chatter. This method is beneficial for longer workpieces when there is not any support except the chuck. Vibration-assisted machining can be used to minimise the problems caused by vibrations. VAM combines precision machining with small-amplitude tool vibration to improve the fabrication process. It has been applied to some processes ranging from turning, drilling to grinding. Based on the enumerated above we made some trial measurements about the basic vibrations of the turning tool shank. The tests were done on an NCT EUROturn-12B CNC machine which can found in the workshop of our institute. The tested material was Polyamide 6 because this is the most commonly used polymer in the industry. In the future, we would like to test some other basic and composite polymer materials too. The equipment was served by a specialist from SPM Budapest Kft. With these tests, our goal was to make sure that the equipment and the measuring setup are suitable for our future research.

\section{Introduction}

In turning processes, there are some unnecessary phenomena. For instance, the chatter due to the vibrations between the tool and the workpiece. This is because of the interaction between the machined material, and the machine tool causes a dynamic instability. The so-called self-excited effect limits the productivity rate, decrease the tool life and result in poor surface quality $[6,7]$. There are some methods to avoid the chatter effect. One of the methods is Spindle Speed Variation (SSV). In case of SSV, the CNC machine can increase and decrease the speed of spindle continuously during turning which can significantly reduce the effects of chatter. This method is very useful for longer workpieces when there is no any support except the chuck. One other method is Vibration Assisted Machining (VAM). VAM combines precision machining with small-amplitude tool vibration to improve the fabrication process [3]. There are some other methods also, but the goal always is to suppress the unnecessary chatter effect [4]. The chatter depends on the machining parameters, the vibrations from the environment, the robustness of the machine, the material of workpiece and tool, etc. [5]. In a turning process, one of the most important output is the quality of the finished surface. It very strongly depends on the vibrations. Tool-tip vibrations still cannot have determined exactly. Moreover, the 
dependence of surface roughness, waviness and other surface errors on tool vibration is not completely clarified [2].

To avoid, or count with chatter, we must know the vibrations. In this article, we made a trial measurement for getting information about this effect.

\section{Methods}

The tests were run on a type NCT EUROturn-12B CNC lathe machine. This device is located at the workshop of the Institute for Mechanical Engineering Technology at Szent István University. We used a standard SCLCR1616H09 tool shank with a type CCGT 09 T3 04 AS IC20 turning insert. This insert is recommended for aluminium workpieces. However, it is also good for basic polymer materials. The industry often uses it for polymers if it is economically better than an insert, especially for polymer

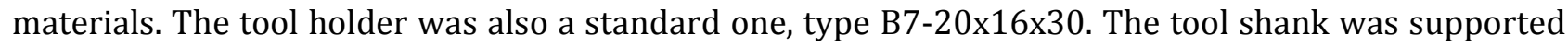
only on $50 \mathrm{~mm}$ from the total $100 \mathrm{~mm}$ length to place the magnetic-based vibration meter. The measuring equipment was served by a specialist from SPM Budapest Kft. The first figure shows the used equipment.

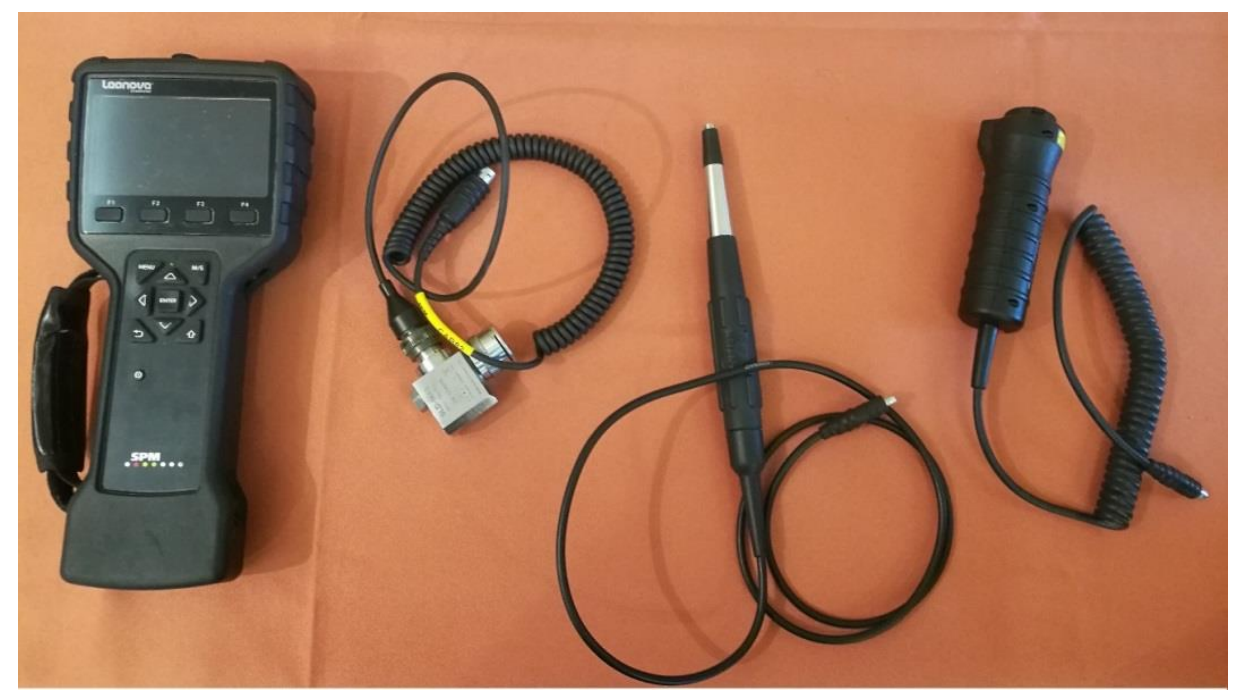

Figure 1. The measuring equipments (from left: Leonova Diamond - DIA 300 processing unit, SLD-144S vibration measuring unit, TRA73 shock pulse meter and TTP10 laser tacho/temperature meter)

The tested material was cast polyamide 6 because in case of machined polymer elements this is the most commonly used basic polymer in the industry. The properties of the polymer chip vary by a large extent accordingly to certain parameters. During machining, elementary chip formation is favourable, while the fast-flowing chip is the least desirable. This type gets curled up and stuck in between other parts of the processing machine very easily and can even cause fracturing of tools and smaller workpieces. For safety reasons, we saw the workpiece across to the middle in an axial direction making the flowing chips break at each rotation. We also used this method in our previous cutting force measuring tests [1]. The geometry of the workpiece can be seen in figure 2 . 
International Journal of Engineering and Management Sciences (IJEMS) Vol. 4. (2019). No. 1

DOI: 10.21791/IJEMS.2019.1.25.

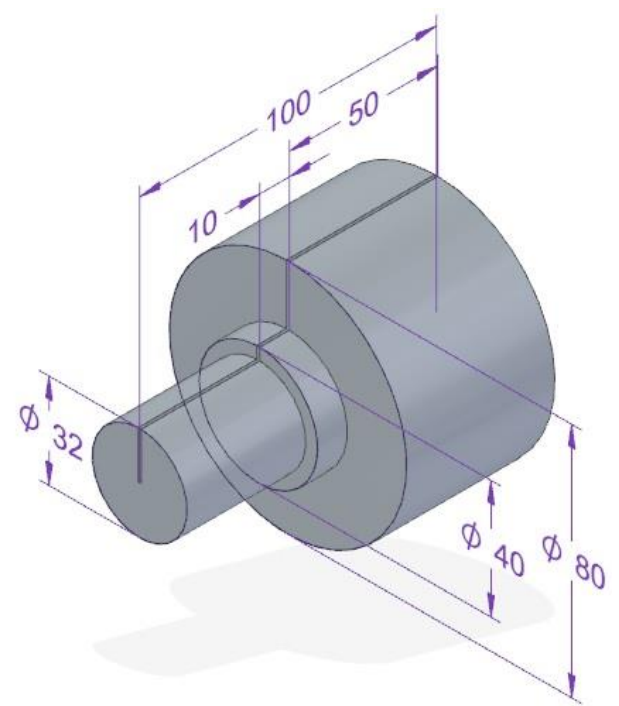

Figure 2. The geometry of the workpiece

At first, we measured the acceleration, speed and amplitude of the vibrations (later: vibrations) in the axial direction and the shock pulse in the tangential direction (figure 3.).

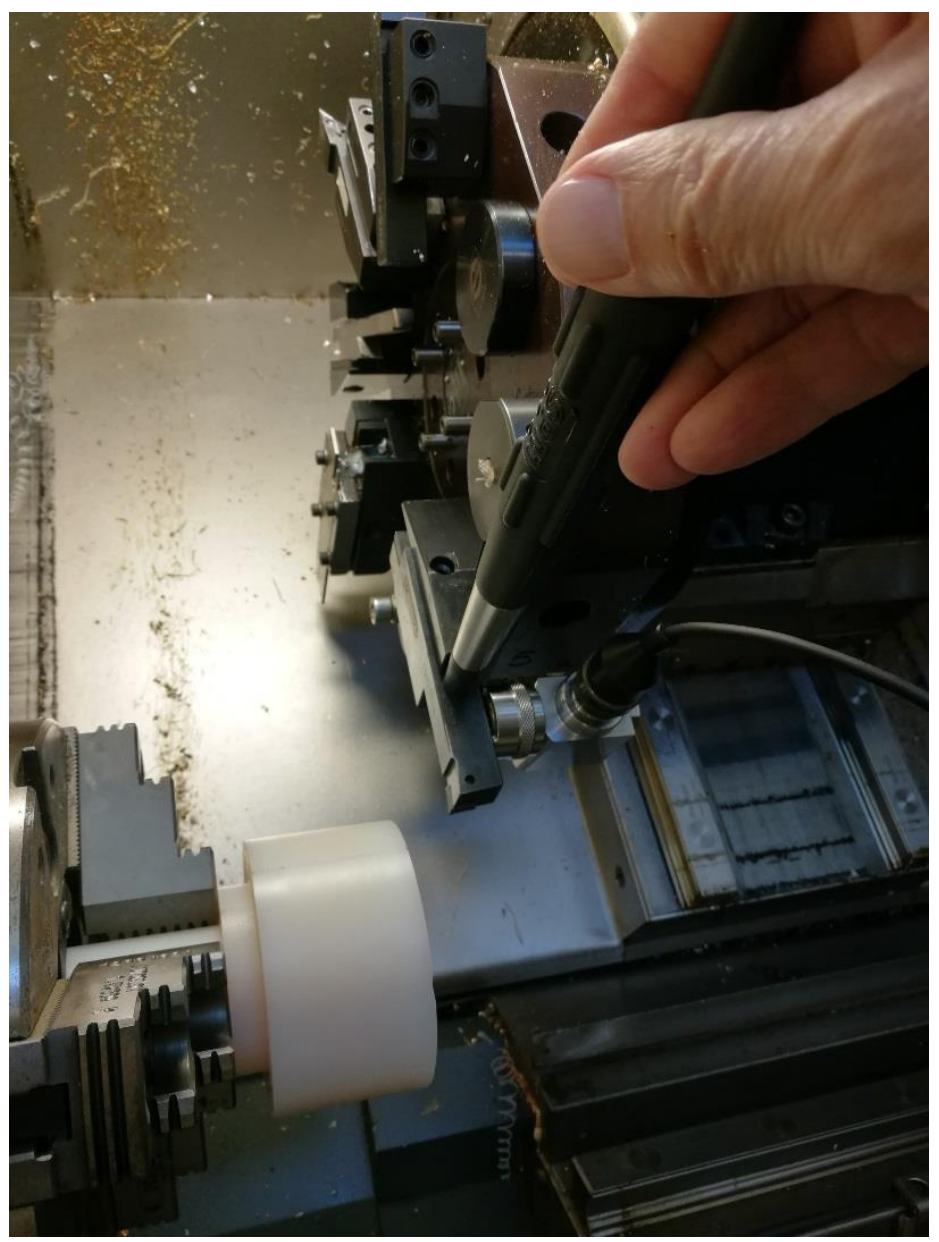

Figure 3. The setup for measuring the shock pulse in the tangential direction, and the vibrations in the axial direction (the spindle speed was also measured continuously) 
After that, we changed the devices. As we expected, the second method proved to be a more convenient solution (figure 4). We held the measuring devices in our hands for taking the pictures about the setups.

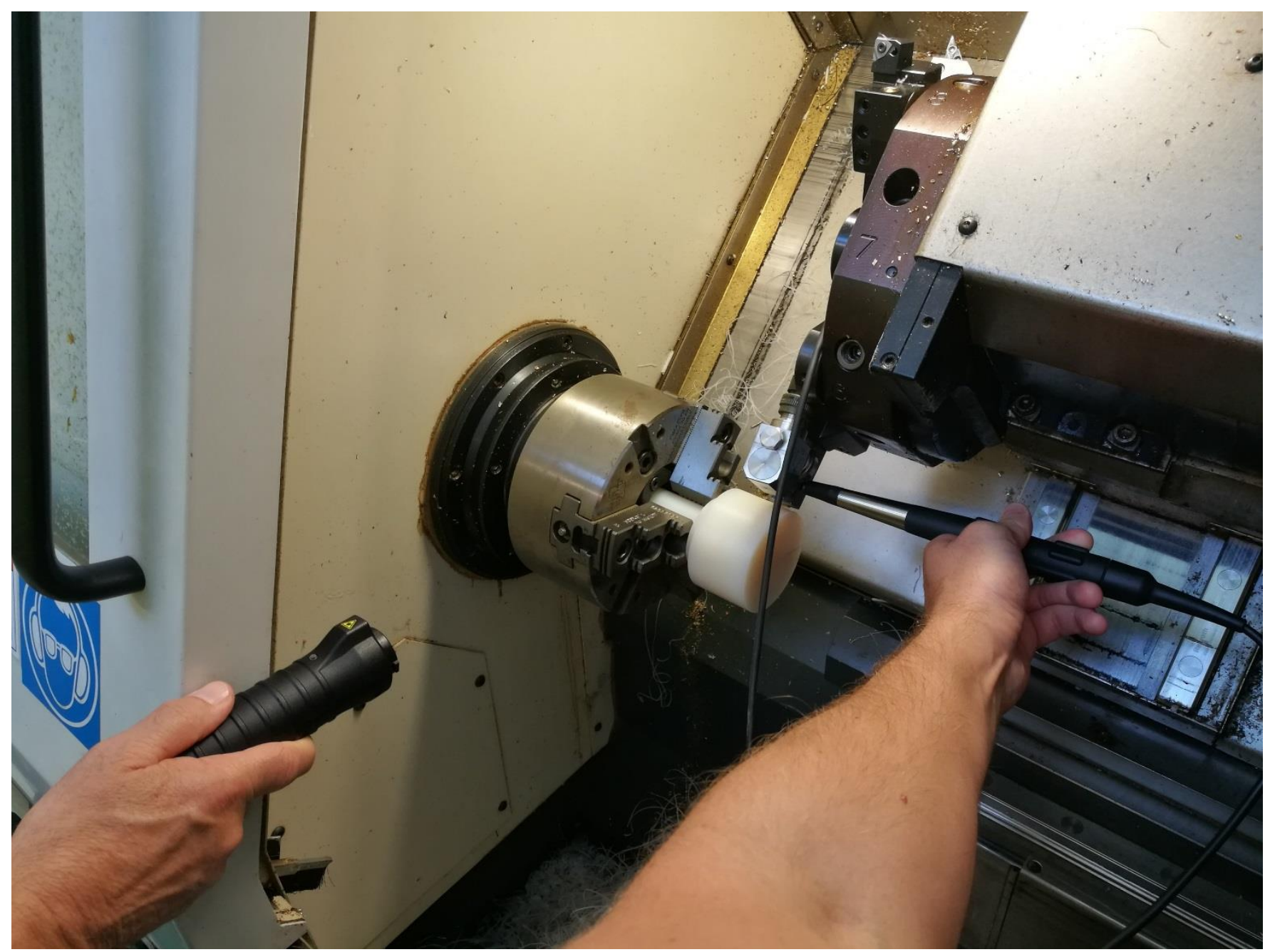

Figure 4. The setup for measuring the spindle speed, the vibration in the tangential direction, and the shock pulse in the axial direction

The measuring equipment was connected to the processing unit. The tests were run step by step. First, we measured the spindle speed, and after that, we measured it continuously. The second was the shock pulse and finally the vibrations. These steps are a must. The processing unit displays the time what is required for the three steps. Therefore, in this case, the feed rate gave us a limit. If the feed rate is too big, we have not enough time to finish the actual test.

For this reason, we decided to measure only the spindle speed and the vibrations. Measuring the spindle speed is necessary. There are two phases in case of spindle speed measure. First, we must measure only the spindle speed, then the spindle speed continuously while other measurements are in progress. However, we can finish the pre-measurement of spindle speed before the turning tool touch the workpiece. To measure the spindle speed, we put a reflective patch to the chuck. 
The parameters of the tests were $150 \mathrm{~m} / \mathrm{s}$ cutting speed, $1 \mathrm{~mm}$ depth of cut and 0,1 $\mathrm{mm} / \mathrm{rev}$ feed rate. The cutting speed was calculated by the spindle speed and the actual diameter of the workpiece.

\section{Results}

To get the results, the processing unit was connected to the computer. The specialist uses their special SPM software called Condmaster Ruby. The next two figures show the speed of vibration in the function of time.

$A 1=0,098 \mathrm{Sec}-0,654 \mathrm{~mm} / \mathrm{s} \quad A 2=0,196 \mathrm{Sec}-0,145 \mathrm{~mm} / \mathrm{s} \quad A 2-A 1=0,098 \mathrm{Sec}(10,18 \mathrm{~Hz}) \quad 0,509 \mathrm{~mm} / \mathrm{s}$

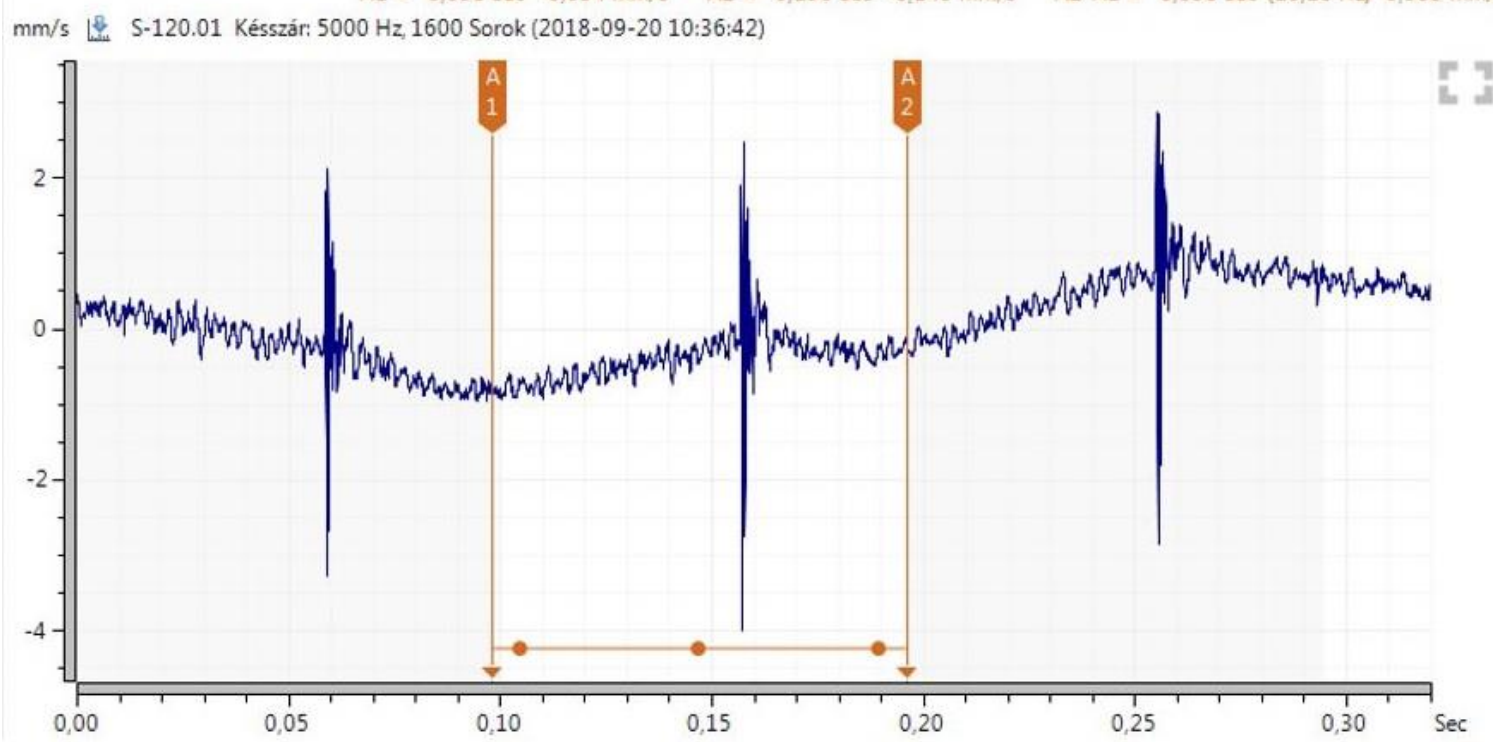

Figure 5. The speed of vibration in the function of time in case of the first setup

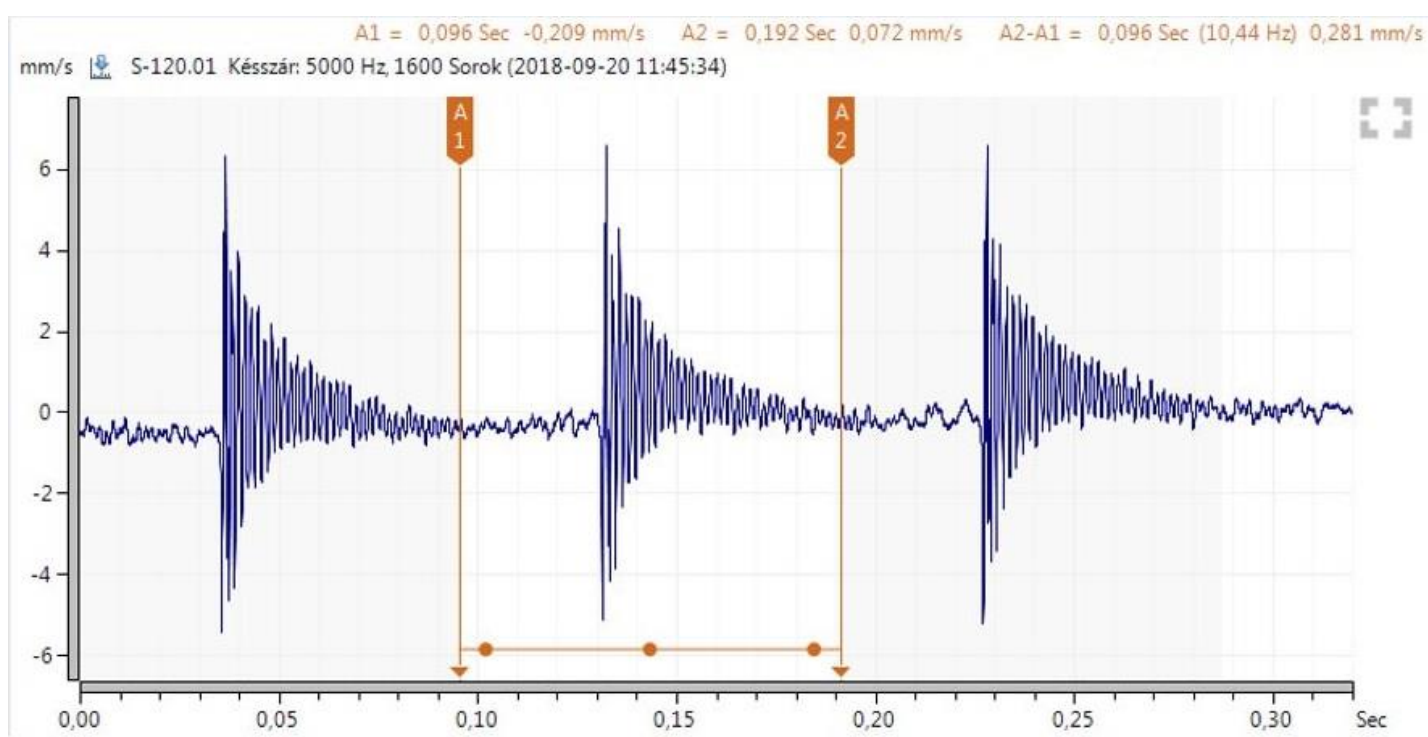

Figure 6. The speed of vibration in the function of time in case of the second setup

Figure 6. is more relevant to our future work because as I mentioned before, in this case, the vibrations were measured tangentially. It can be seen, that the tool shank behaves like a spring. We can recognise a damped vibration. This is because of the sawing. The effect of sawing was too much, compared to the 
vibrations far from the sawing in the workpiece. When the machining parameters, such as cutting speed or depth of cut, were adjusted, the effect was bigger and bigger. It was too significant to evaluate.

For the other data of vibration: the displacement was $8,36 \mu \mathrm{m}$, the average velocity was $0,9 \mathrm{~mm} / \mathrm{s}$, the peak velocity was $6,58 \mathrm{~mm} / \mathrm{s}$ and the acceleration was $4,72 \mathrm{~m} / \mathrm{s}$.

\section{Conclusions}

After some tests, we found that the shock pulse is too low, so later we measured only the vibration in tangential direction while the spindle speed was also measured continuously. With these tests, our goal was to make sure that the equipment and the measuring setup are suitable for our future research.

After processing the data, we found that the vibrations are also very low, because of the polymer workpiece and the parameters we used in these tests. The structure of a modern CNC machine is also an influencing factor. When higher cutting speeds or higher depths of cut were applied, the influence of the sawing was too significant.

In the future, we should use longer workpieces for higher feed rates.

As a final conclusion, the measuring method and setup were suitable for measuring the tangential vibrations of the tool shank. However, we must use workpieces without sawing.

In the future, we would like to test some other basic and composite polymer materials too. We will avoid the sawing to get the best results.

\section{References}

[1] Á. Sarankó - R. Keresztes - G. Kalácska, Machining of engineering polymers, International Scientific Conference on Advantages in Mechanical Engineering, 4

[2] C. L. He - W. J. Zong - J. J. Zhang, Influencing factors and theoretical modeling methods of surface roughness in turning process: State-of-the-art, International Journal of Machine Tools and Manufacture, 24

[3] D. E. Brehl - T. A. Dow, Review of vibration-assisted machining, Precision Engineering, 153

[4] D. Kono - S. Nishio - I. Yamaj i- A. Matsubara, A method for stiffness tuning of machine tool supports considering contact stiffness, International Journal of Machine Tools \& Manufacture, 1-2

[5] G. Stephan - A. K. Kiss - B. Ghalamchi - J. Sopanen - D. Bachrathy, Chatter avoidance in cutting highly flexible workpieces, CIRP Annals - Manufacturing Technology, 380

[6] M. Siddhpura - R. Paurobally, A review of chatter vibration research in turning, International Journal of Machine Tools \& Manufacture, 28

[7] K. H. Hajikolaei - H. Moradi - G. Vossoughi - M. R. Movahhedy, Spindle Speed Variation and adaptive force regulation to suppress regenerative chatter in the turning process, Journal of Manufacturing Processes, 106-107 